\title{
Technical Tips in Laparoscopic Donor Right Hepatectomy in Living Donor Liver Transplantation
}

\author{
Hae Won Lee, Ho-Seong Han*, Jai Young Cho
}

Department of Surgery, Seoul National University Bungdang Hospital Seoul National University College of Medicine, Seongnam, Korea

\section{ABSTRACT}

Although laparoscopic donor right hepatectomy (LDRH) is increasingly performed in adult living donor liver transplantation, most experiences have been reported from a limited number of major transplant centers. This is because LDRH requires high-level surgical skills and a guarantee of donor safety. Thus, despite its many advantages, this operation program should be performed with caution, especially in less experienced centers. Various surgical techniques and the know-how have been introduced by several publications in recent years, which include donor's position during operation, selection of port sites and division methods of bile duct and vascular structures. Even though the technical consensus on LDRH has not been established yet, the accumulated experience of major LDRH centers is a good starting point to guide surgeons planning a new LDRH program.

Key words: laparoscopy, laparoscopic skill, surgical technique, live donor, donor hepatectomy, right hepatectomy

\section{INTRODUCTION}

Living donor liver transplantation (LDLT) is the most common option to overcome the scarcity of deceased donor. Since the first LDLT using a left lateral section graft was successfully performed in a child with biliary atresia, (1) it has rapidly expanded, even in adult-to-adult LDLT using left or right liver grafts. However, LDLT inevitably accompanies the donor's sacrifice. The donor should not only accept the risk of morbidity and mortality but also suffer operative scar, pain, and a long period of recovery. These problems might lead to hesitation of potential donors and prevent more expansion of LDLT. Hence, many transplant surgeons have attempted less invasive surgeries in LDLT to improve the quality of life of living donors.

With the accumulation of experience and technical development, the indication of laparoscopic hepatectomies has gradually expanded. Laparoscopic left lateral sectionectomy (LLS) has been already accepted as a standard option (2). In recent years, hepatectomies for unfavorably located tumors and major hepatectomies are being tried laparoscopically without contraindication. Even in LDLT, laparoscopic donor hepatectomy (LDH) has been increasingly performed since the first successful laparoscopic donor LLS was introduced in 2002 (3).

\author{
*Corresponding author: \\ Ho-Seong Han, M.D., Ph.D. \\ Professor \\ Department of Surgery \\ Seoul National University Bundang \\ Hospital \\ Seoul National University College of \\ Medicine \\ 82, Gumi-ro 173 Beon-gil, \\ Bundang-gu, Seongnam-si \\ Gyeonggi-do, 13620, Korea \\ Phone: +82-31-787-7091 \\ Fax: +82-31-787-4078 \\ E-mail: hanhs@snubh.org

\section{Abbreviations:} \\ SNUBH: Seoul National University \\ Bundang Hospital; \\ CUSA: Cavitron Ultrasonic Surgical \\ Aspirator; \\ ICG: Indocyanine green; \\ IOC: intraoperative cholangiography.
}


Laparoscopic hepatectomy has several obvious advantages including less pain, smaller scar and earlier return to normal social activity, (4) which may be much more attractive to healthy donors than patients with some diseases to be treated. However, because the donor safety is the most important issue in LDLT and donor hepatectomy is more complex compared to simple hepatectomy, LDH should be performed in highly experienced centers with caution (5-7).

In $26^{\text {th }}$ World Congress of the International Association of Surgeons, Gastroenterologists and Oncologists (IASGO 2016), held in Seoul, 2016, expert panels reached a consensus that laparoscopic donor LLS could be considered a standard in pediatric LDLT (7). However, they also agreed that laparoscopic donor right hepatectomy (LDRH) is still an innovative procedure in a developmental phase $(7,8)$. Although we began pure LDRH in 2010, $(9,10)$ we truthfully admit that LDRH requires the high level of surgical skill and there is little evidence on its safety so far. The technical consensus on LDRH has not been established yet and its clinical application remains challenging for many surgeons without sufficient experiences. Thus, we here introduce technical tips performing LDRH in major centers, together with our experience, to reduce trial and errors and to facilitate safe LDRH.

\section{Timing to initiate totally laparoscopic donor right hepatectomy and learning curve}

Since even LDRH could ensure donor safety, it is generally agreed that LDRH should be performed by surgeons extensively experienced for both laparoscopic liver resection (LLR) and open donor hepatectomy (7). Inexpertness in either one of those fields might not be recommended to perform that operation. Thus, the timing to initiate a LDRH program in donor surgery for LDLT should be prudently decided. However, it is still unclear how much experience is needed before starting LDRH.

Two ways that LDLT centers could initiate LDRH safely has been introduced. One is a way that the surgical team starts a LDH program first in pediatric LDLT requiring left lateral section graft (11). Although many surgical techniques are different between donor surgery and conventional hepatectomy for liver disease, laparoscopic LLS is relatively easy even in a donor surgery and it has been already considered a standard practice for LDLT (7). After acquiring surgical proficiency with LLS, they could try a stepwise extension to left hepatectomy and then ultimate right hepatectomy for adult LDLT. This approach method might be suitable for a large volume LDLT centers performing not only adult LDLT but also pediatric one. Some surgeons proposed a different stepwise approach because there are many centers that are performing few pediatric LDLT. They emphasized that the team could acquire sufficient experience through laparoscopyassisted donor right hepatectomy (LADRH) before initiating pure $\operatorname{LDRH}(6,7,12,13)$. In this approach, a move from LADRH to LDRH might be gradually achieved. The conversion to laparotomy could be made at any step the surgeon has difficulty to proceed with laparoscopic operation. The proportion of laparoscopic procedures is step by step increased based on the surgeon's incremental experience until at last the whole operation can be safely completed under the laparoscopy $(6,12)$. Because the team can gradually accomplish the learning curve for LDRH through LADRH while ensuring donor safety, this stepwise approach might be easily adopted even in LDLT centers with relatively less experience of laparoscopic hepatectomy.

Pure LDRH might be tried earlier in centers that have performed various liver surgeries under the laparoscopy. However, our recent study showed that the technical proficiency in major hepatectomy would be especially important for safe LDRH (14). The outcomes of LDRH including operation time, blood loss, and hospital stay have been significantly improved after the learning curve of the laparoscopic major hepatectomy although the rate of major complication was similar (14). Therefore, considering the donor safety, we advise the team planning a LDRH program that they should start it after passing through the learning curve for laparoscopic major hepatectomy. Some LDLT centers thought that they reached the learning curve for LDRH at 20-30 case in the early period of $\operatorname{LDRH}(12,15,16)$. However, recent studies showed that much more experience might be needed to achieve it $(17,18)$. Hong et al. $(17)$ recently reported the analysis of the learning curve for LDRH by a cumulative sum method. They investigated the actual operating time of each surgery after 100 consecutive LDRH cases by a single surgeon. When the average operating time was set as the cut-off value, the cumulative sum graph displayed a continuous descent after about 60 operations, which could mean that the stable learning curve for LDRH was achieved just after 60 cases. In addition, it was extended to 65-70 cases after adjustment of risk factors such as a big liver and double portal veins (17). However, there is a factor to be considered with caution in their study. The surgeon who performed the study had experiences of more than 1,000 open donor hepatectomies and more than 200 laparoscopic hepatectomies for hepatic tumors 
before adopting a LDRH program. Therefore, it would take longer time for surgeons with relatively less experience to reach the learning curve for LDRH. Because LDRH requires a high level of surgical skill, surgeons should not make a haste to start a LDRH program. The step-by-step transition is recommended rather than a rush.

\section{Positioning of a donor and selection of port sites}

Based on the literature reported up to date, there is no difference in the donor positioning between LDRH centers. The donor is placed supine with his legs apart. The main surgeon stands between the donor's legs with the endoscopist and the assistant on the left side of the donor and the scrub nurse on the left side of the operator $(11,16,19,20)$. The donor is positioned reverse Trendelenburg by $15-30^{\circ}$ with the left side tilted downward $(11,19-21)$. This position can facilitate mobilizing the liver by allowing easy access to right upper and posterior area of the liver (19). Carbon dioxide pressure for the pneumoperitoneum is maintained at 11-12 $\mathrm{mmHg}$ us in most centers, while some centers may prefer higher pressure $(11,16,19-22)$. We usually maintain the pressure at $13 \mathrm{mmHg}$.

The 5-port system is used in most routine cases even if the size and the location of trocars may be slightly different between centers (fig. 1). The selection of port sites can be highly variable center by center and case by case. However, major centers with high volume of LDRH tend to standardize port placement. Most centers use 10-12 mm trocars for the laparoscopic camera and two working ports of the operator although we sometimes use a $5 \mathrm{~mm}$ trocar as the minor working port. The camera port is usually placed at the umbilicus and it might be interspersed from supraumbilical to infraumbilical location considering the length of the donor's upper midline (21). The main working port for the operator's right hand is the most important in the 5port system because almost all devices including parenchymal dissecting instruments and vascular clips and staplers are introduced through that one. However, its location may be somewhat variable between centers. Lee at al. (21) from Seoul National University suggested that the main working port would be good for working at the location of a few centimeters below the right costal margin, above the gallbladder fossa although it might be placed more medially near midline of the donor in some centers $(16,19)$. The optimal location of the main working port should be dependent on the operator's preference as well as the size of the

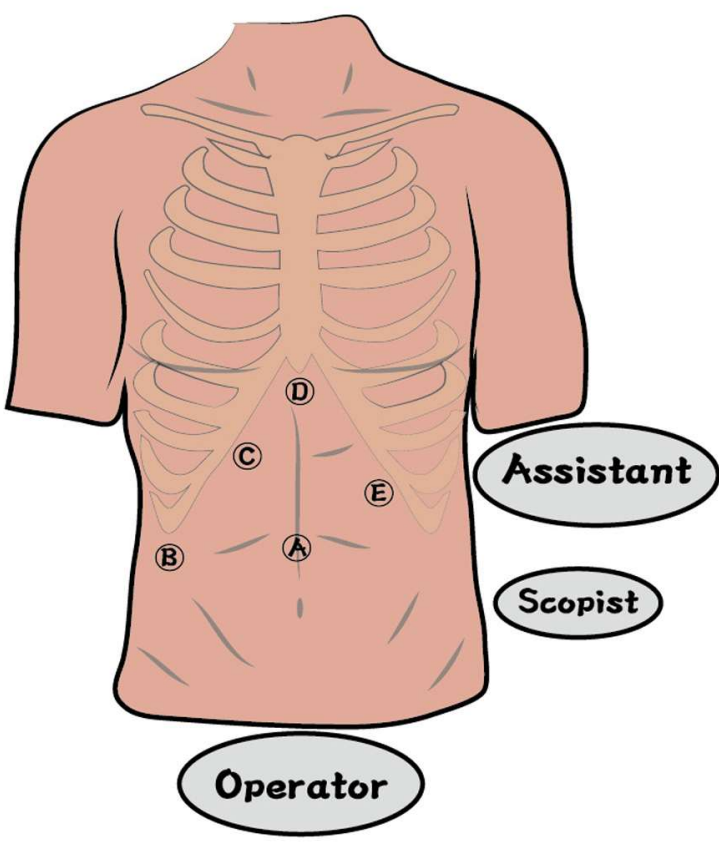

Figure 1 - Five port system for laparoscopic donor right hepatectomy of Seoul National University Bundang Hospital

Fiver trocars are inserted as illustrated. A, $12 \mathrm{~mm}$ camera port; B, $5 \mathrm{~mm}$ minor working port; C, $12 \mathrm{~mm}$ main working port; D, $11 \mathrm{~mm}$ assistant port; $E, 5 \mathrm{~mm}$ assistant port.

donor's body cavity and the liver anatomy. Actually, we prefer the subcostal area just lateral rectus abdominis muscle for its location. The minor working port for the operator's left hand is usually placed at the subcostal area below the liver tip in the right anterior axillary line. Two additional ports are placed at the epigastric area just below the xyphoid process for the assistant's right hand and at the subcostal area in the left midclavicular line for the assistant's left hand. Although some centers use an 11-12 mm trocar for the assistant's right hands, $5 \mathrm{~mm}$ trocars are usually used for the assistant's ports $(16,19,21)$.

Soubrane and Kwon (19) introduced another option for port position. They described that they could insert $10 \mathrm{~mm}$ trocar in the anterior right axillary line for the camera, two $12 \mathrm{~mm}$ operative trocars, one on each side of the camera port, and two $5 \mathrm{~mm}$ assistant trocars in the right flank and on the midline, below the xyphoid process. They suggested that this option might be useful for the use of $30^{\circ}$ straight camera. Lee et al. (21) emphasized one-by-one port placement. After liver mobilization, it might be quite difficult to use the early inserted trocars due to the positional change of the liver. Thus, they changed the port placement method from all-at-once system in the early period of their experience to one-by-one system. They introduced the timeline of trocar insertion in pure 3-dimentional LDRH; 
umbilical camera port, $1^{\text {st }}$ assistant port for left hand, main working port, $2^{\text {nd }}$ assistant port for right hand and minor working port in order during liver mobilization (21).

\section{Liver mobilization and dissection of the hilum}

The liver mobilization include division of the falciform, coronary and right triangular ligament and exposure of right and middle hepatic vein (RHV, MHV) and inferior vena cava (IVC). It is performed by energy devices or electrocautery based on operator's preference. Various accesses with different axis are needed for full mobilization. The assistant port of left upper abdomen would be useful to dissect between the falciform and upper coronary ligament and the suprahepatic IVC. The epigastric port might give a better access to right lateral coronary ligament. In addition, the minor working port might be effective in dissection of the internal part of right triangular ligament and full exposure of IVC by the operator's left hand, while the main working port is used for countertraction (21). The anterior aspect of IVC should be dissected by dividing small short hepatic veins. Large right inferior hepatic veins may be saved and later transected with RHV for effective venous drainage. Left tilted position could give a better vision when dissecting right lateral and posterior aspect of the liver (19). Liver traction should be performed very cautiously during mobilization to avoid parenchymal injury. Fan retractor used by the assistant is helpful to make a good operating field safely. Some centers prepare hanging maneuver by completely tunneling between MHV and RHV above the IVC at the end of the liver mobilization, $(20,23)$ while other centers do not use it or prepare it at the end of parenchymal dissection $(11,16,24)$.

After liver mobilization, cholecystectomy is performed. The right side of the hepatic hilum is dissected. First, the Calot's triangle is dissected and the cystic artery is divided. The cystic duct is either divided with the cystic artery or kept intact. The cystic duct might be used later for intraoperative cholangiography. Some centers do not remove the gallbladder clearly and remain it attached to the right liver to use as a retractor during operation $(16,19,23)$. Then, the right hepatic artery and portal vein (RHA, RPV) are gently dissected and taped (fig. 2). Electrocautery should be used with caution in this step not to injure inflow vessels, especially the RHA. Small caudate branches of the portal vein should be cut to make the RPV long enough for later anastomosis $(11,19)$. The hepatic resection line can be visualized by transient clamping the RHA and RPV with laparoscopic bulldog clamps. Some centers inject indocyanine green (ICG) and they suggest it could show more exact midplane under near-infrared camera $(20$, 25) Intraoperative ultrasonography can be used to identify the location of the middle hepatic vein and branches from segment 5 and 8 before parenchymal dissection $(11,16,19)$.

\section{Parenchymal dissection and division of the bile duct}

Various devices can be used for dissection of the hepatic parenchyma. Many centers use energy devices

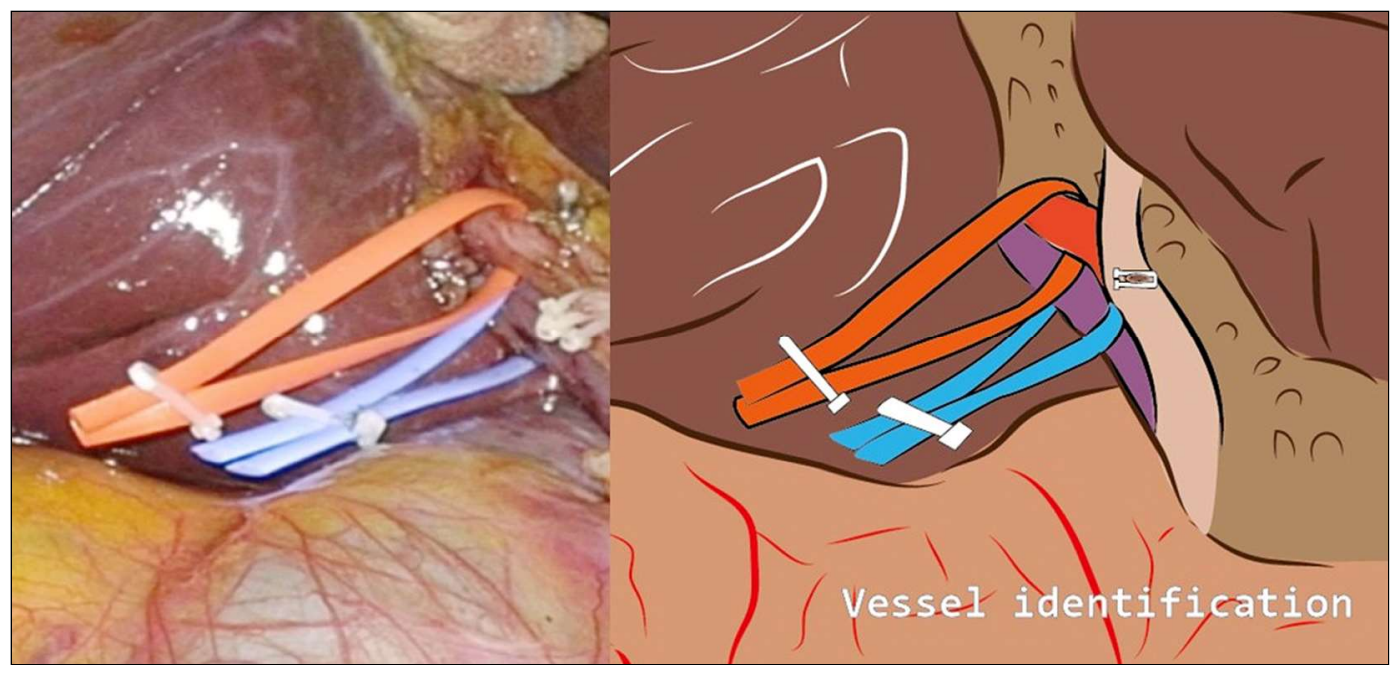

Figure 2 - Identification of right hepatic artery and portal vein

The right hepatic artery and portal vein were encircled by red and blue rubber bands, respectively 
like ultrasonic shears for the capsule and superficial parenchyma and use a cavitron ultrasonic surgical aspirator for deeper area $(11,19,20)$. Some centers reported they preferred an ultrasonic energy device even for deeper portion and they used an ultrasonic surgical aspirator only for fine delicate dissection around the hilum $(16,22)$. Parenchymal transection is made from the anterior surface to the hepatic hilum and the IVC along the MHV. Sizeable branches of MHV from segment 5 and 8 are carefully dissected and divided to be reconstructed at the back table.

The division of the bile duct might be one of the most challenging procedures in LDRH. Its division can be performed either after about two-thirds of the parenchymal dissection or after complete transection according to the center's preference $(11,16,20)$. Most centers use intraoperative cholangiography (IOC) to verify the optimal cutting point of the bile duct. After carefully identifying the right hepatic duct and the hilar plate, they affix radio-opaque markers such as rubber bands or metal clips to the presumed cutting level and then check IOC by infusing the contrast medium through the cystic duct $(10,11,16,19,22,26)$. Some centers use ICG fluorescence cholangiography instead of IOC to delineate the biliary system in $\operatorname{LDRH}(25,27)$. We also introduced ICG cholangiography recently and it is likely more comfortable to $\mathrm{IOC}$ even if additional equipment is required (fig. 3). After the accurate bile duct division point is determined based on IOC or ICG cholangiography, cutting and repair of the remaining stump is performed. However, this procedure may be quite different between centers. Some centers first clamp the bile duct with clips on the remnant side and then cut, while other centers first cut and then close the stump of the remaining bile duct. Furthermore,

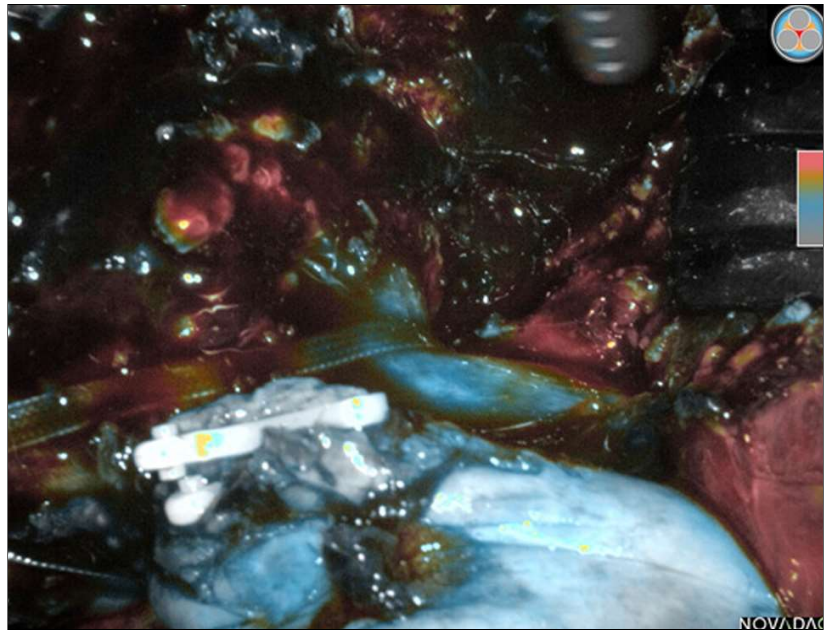

Figure 3 - Indocyanine green fluorescence cholangiography Indocyanine green fluorescence cholangiography help to decide the optimal cutting point of the bile duct by well delineating the biliary structure

some centers use metal or polymer clips for closure of the remaining duct stump, while other centers close it with sutures $(11,16,19,20)$. We prefer to cut first and then suture the bile duct just like in open donor hepatectomy (fig. 4). IOC can be redone after stump closure to detect any leakage or to check the patency of the remnant bile duct.

Recently, Rhu et al (28) reported the change of their procedure from "clip and cut" to "cut and clip" technique. In the "cut and clip" technique, they cut the bile duct and left it open, both on the graft and remnant liver side, during operation and finally closed the opening of the remnant duct with metal clips after graft extraction. They mentioned that this technique did not require IOC and improved the outcomes in terms of fewer bile duct opening and less biliary stricture of the

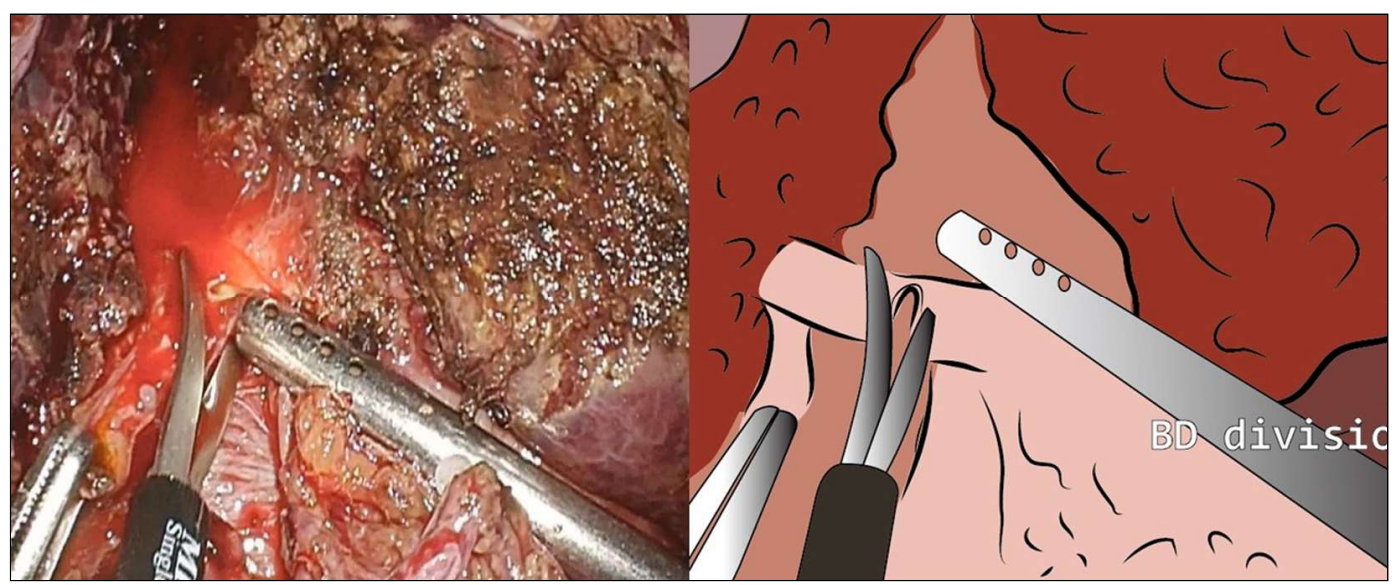

Figure 4 - Division of the right bile duct

The right bile duct is cut at the optimal point and the the remaining stump is closed with suture 


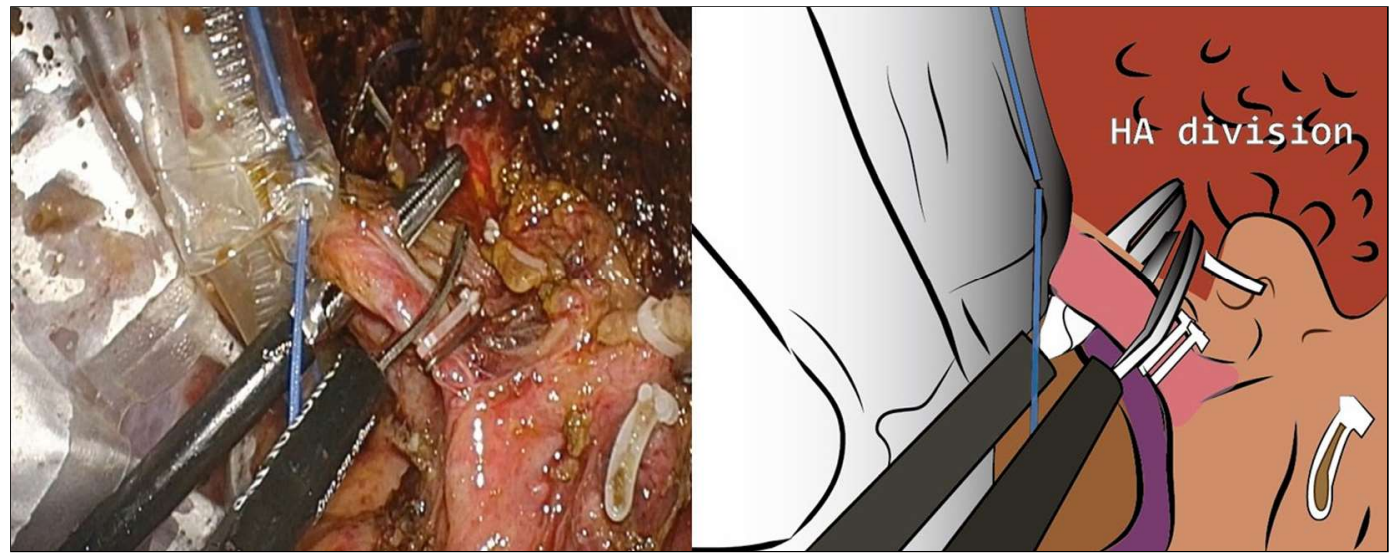

Figure 5 - Division of the right hepatic artery

The right hepatic artery is cut after applying polymer clips at the remnant stump

recipients (28). However, no gold standard technique of the bile duct division has been established yet. We think the duct division method could be tried differently based on center's experience and the status of the donor's bile duct.

Although most centers performed LDRH only for donors with a normal anatomy in the early period, some experienced centers have tried LDRH for donors with anatomical variations in recent years (20). There are several case reports that introduced successful LDRH experience for donors with Type II or III bile duct variation $(22,25,26)$. Hence, the bile duct variation might not be considered contraindication for LDRH. However, expanding of the indication to donors with an atypical anatomy should be made with caution because increased postoperative complication rate has been reported after LDRH in anatomically unfavorable donors $(12,16)$.

\section{Division of Vessels and Graft Extraction}

When the bile duct is divided and parenchymal dissection is completed, the right liver graft is ready for retrieval. The graft is extracted through the suprapubic Pfannenstiel incision of $10-12 \mathrm{~cm}$ sized to maximize cosmetic effect and that incision is prepared before division of hepatic vessels to minimize ischemic time. Some centers make suprapubic incision except for the peritoneum to maintain pneumoperitoneum and then open the peritoneum just before graft extraction after hepatic vessel division $(13,26,29)$. Some other centers might temporarily close the suprapubic incision after trocar insertion (19) and use a laparoscopic gel port system for pneumoperitoneum.

The right liver is put into the plastic bag before vascular clamping or disconnection to minimize warm ischemic time. After intravenous heparin infusion, the hepatic artery is first cut and then the portal and

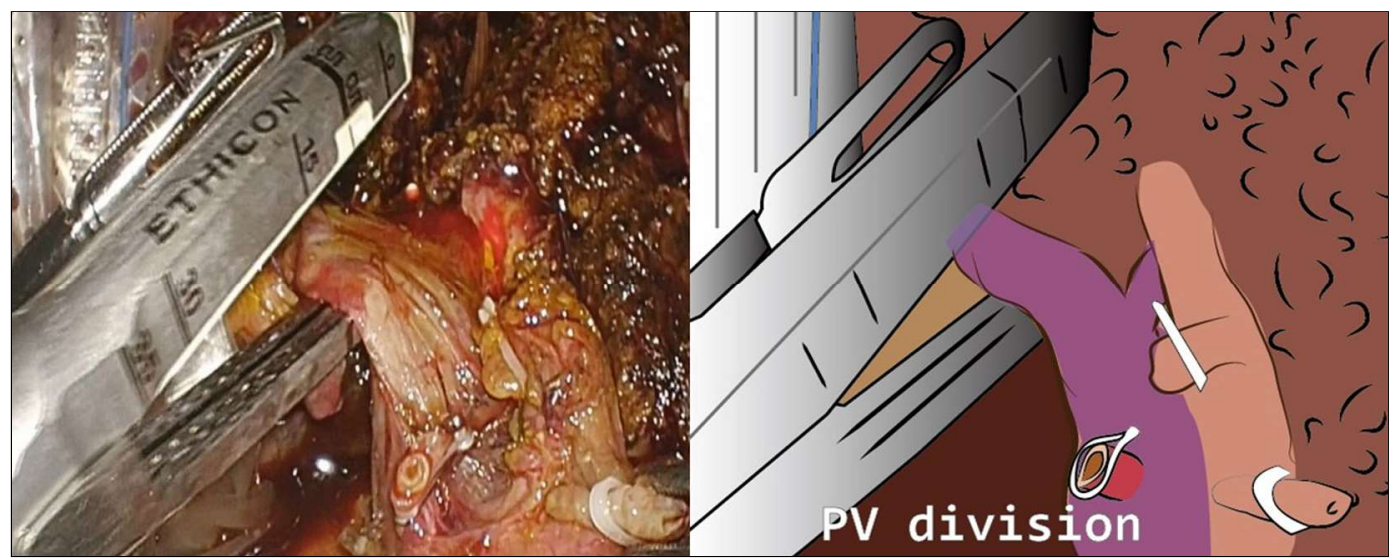

Figure 6 - Division of the right portal vein

The right portal vein is divided by a linear stapler after hepatic artery division 


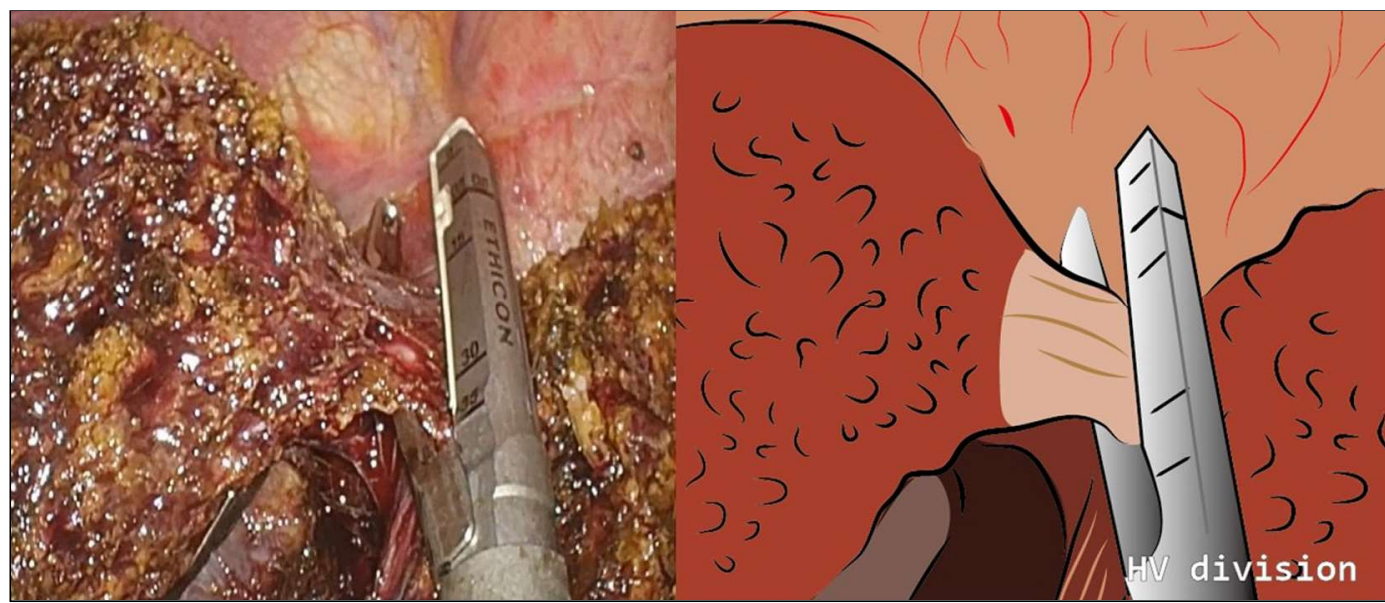

Figure 7 - Division of the right hepatic vein

The right hepatic vein is divided last by a linear stapler.

hepatic veins are divided. Almost all centers are known to use polymer clips to divide RHA (fig. 5). However, most centers use linear staplers for the portal and hepatic vein division, while some centers use polymer clips for the portal vein division (fig. 6 and 7$)(11,13,20$, 29-32). The technical differences between centers are shown in table 1. Some centers usually use a bilateral stapler to divide the portal and hepatic veins. It might be convenient because it does not make bleeding when cutting vessels, while it might shorten the length of vascular stumps by several millimeters because the stapled line must be removed at the bench. Therefore, one-sided staplers or clips could be advantageous in cases with short vascular stumps. In addition, Lee et al. (21) proposed that umbilical port would be more useful to cut the RHV than the main working port, because it can staple parallel to the IVC. The stapling ports should be considered flexibly according to the direction of vascular structure. Especially when stapling the portal vein, great care should be taken not to make any torsion or stricture of the remnant portal vein $(19,20)$. The best technique managing vessels has not established even if various methods have been introduced from major centers so far. It will be important to decide the most optimal and caseoriented method based on surgeon's experience.

Recently, experienced centers reported successful experiences for donors with the portal vein variation considered unsuitable for LDRH in the beginning period (33-35). They suggested that although the right anterior portal vein is not accessible during hilar dissection, the resection plane could be visualized under the near-infrared camera by clamping the main portal vein and RHA before ICG injection (33). In addition, they introduced a new technique consisting of temporarily clipping with polymer clips, intracorporeal suturing after graft retrieval and then clip removal. They suggested that even separate right anterior and

Table 1 - Surgical techniques for totally laparoscopic donor right hepatectomy

\begin{tabular}{|c|c|c|c|c|c|c|}
\hline \multirow[t]{2}{*}{ References } & \multirow{2}{*}{$\begin{array}{c}\text { Main Parenchymal } \\
\text { dissection }\end{array}$} & \multirow{2}{*}{$\begin{array}{c}\text { Hanging } \\
\text { maneuver }\end{array}$} & \multirow{2}{*}{$\begin{array}{c}\text { Intra-operative } \\
\text { bile duct imaging }\end{array}$} & \multicolumn{3}{|c|}{ Division methods } \\
\hline & & & & Bile duct & Portal vein & Hepatic vein \\
\hline SNUBH & CUSA & Yes & ICG & Cut and suture & Bilateral stapler & Bilateral stapler \\
\hline Suh et al.(20) & CUSA & Yes & ICG & Clip and cut & Bilateral stapler & Unilateral stapler \\
\hline Kim et al.(11) & CUSA & Yes & IOC & Clip and cut & Polymer clips & Unilateral stapler \\
\hline Rhu et al.(30) & Ultrasonic dissector & No & IOC & Cut and clip & Unilateral stapler & Unilateral stapler \\
\hline Rotellar et al.(31) & CUSA & Yes & ICG, IOC & Cut and suture & Bilateral stapler & Bilateral stapler \\
\hline Samstein et al.(32) & CUSA & Yes & IOC & Clip and cut & Bilateral stapler & Bilateral stapler \\
\hline Takahara et al.(13) & CUSA & No & IOC & Cut and clip/suture & Bi-/unilateral stapler & Bi-/unilateral stapler \\
\hline Song et al.(29) & CUSA & Yes & IOC & Clip and cut & Polymer clips & Bilateral stapler \\
\hline
\end{tabular}

This table was based on the most recent technique if authors described technical changes in their experience. 
posterior portal veins could be divided safely without any torsion or stricture by this technique (34). However, the portal vein variation might be still considered one of relative contraindications for LDRH. A portal vein complication of the donor could lead to a disastrous outcome. Therefore, special attention is needed in performing LDRH for donors with portal vein variation.

The right liver graft is extracted though the suprapubic incision after vascular division as soon as possible and immediately perfused with cold preservation solution at the back table. The suprapubic incision is closed, and the pneumoperitoneum is re-made to check any bleeding or bile leak meticulously. After verifying hemostasis and biliostasis, the drain is placed and at last, the operation is over.

\section{CONCLUSIONS}

Currently, major LDLT centers are performing LDRH actively with the know-how of their own. We summarized their techniques introduced in the literature, which will be helpful to less-experienced surgeons and centers considering a LDRH program. LDRH is feasible and can improve donor's satisfaction if done successfully. It is more likely that LDRH will be increasingly performed worldwide with the accumulation of experience. However, because LDRH obviously requires the high level of surgical skill and the donor safety should be the most important goal in LDLT, a rush to LDRH without sufficient preparation should be refrained. We would like to recommend surgeons newly staring LDRH to do it carefully after sufficient learning and preparation.

\section{Conflicts of interest and source of funding}

We have no conflicts of interest.

\section{Ethical approval}

No institutional ethical approval is required for the present article.

\section{REFERENCES}

1. Strong RW, Lynch SV, Ong TH, Matsunami H, Koido Y, Balderson GA. Successful liver transplantation from a living donor to her son. N Engl J Med. 1990;322(21):1505-7.

2. Buell JF, Cherqui D, Geller DA, O'Rourke N, Iannitti D, Dagher I, et al. The international position on laparoscopic liver surgery: The Louisville Statement, 2008. Ann Surg. 2009:250(5):825-30.

3. Cherqui $D$, Soubrane 0 , Husson $E$, Barshasz E, Vignaux 0 , Ghimouz M, et al. Laparoscopic living donor hepatectomy for liver transplantation in children. Lancet. 2002;359(9304):392-6.
4. Martin RC, Scoggins CR, McMasters KM. Laparoscopic hepatic lobectomy: advantages of a minimally invasive approach. $\mathrm{J}$ Am Coll Surg. 2010;210(5):627-34, 34-6.

5. Soubrane 0. Laparoscopic Donor Hepatectomy: The Long and Winding Road. Transplantation. 2017:101(5):900-1.

6. Lei HJ, Lin NC, Chen CY, Chou SC, Chung MH, Shyr BU, et al. Safe Strategy to Initiate Total Laparoscopic Donor Right Hepatectomy: A Stepwise Approach From a LaparoscopyAssisted Method. World J Surg. 2020;44(9):3108-18.

7. Han HS, Cho JY, Kaneko H, Wakabayashi G, Okajima H, Uemoto $\mathrm{S}$, et al. Expert Panel Statement on Laparoscopic Living Donor Hepatectomy. Dig Surg. 2018;35(4):284-8.

8. Wakabayashi G, Cherqui D, Geller DA, Buell JF, Kaneko H, Han HS, et al. Recommendations for laparoscopic liver resection: a report from the second international consensus conference held in Morioka. Ann Surg. 2015;261(4):619-29.

9. Lee B, Choi Y, Han HS, Yoon YS, Cho JY, Kim S, et al. Comparison of pure laparoscopic and open living donor right hepatectomy after a learning curve. Clin Transplant. 2019; 33(10):e13683

10. Han HS, Cho JY, Yoon YS, Hwang DW, Kim YK, Shin HK, et al. Total laparoscopic living donor right hepatectomy. Surg Endosc. 2015;29(1):184.

11. Kim KH, Kang SH, Jung DH, Yoon YI, Kim WJ, Shin MH, et al. Initial Outcomes of Pure Laparoscopic Living Donor Right Hepatectomy in an Experienced Adult Living Donor Liver Transplant Center. Transplantation. 2017:101(5):1106-10.

12. Kwon CHD, Choi GS, Joh JW. Laparoscopic right hepatectomy for living donor. Curr Opin Organ Transplant. 2019;24(2):167-74.

13. Takahara $T$, Wakabayashi $G$, Nitta $H$, Hasegawa $Y$, Katagiri $H$, Umemura $A$, et al. The First Comparative Study of the Perioperative Outcomes Between Pure Laparoscopic Donor Hepatectomy and Laparoscopy-Assisted Donor Hepatectomy in a Single Institution. Transplantation. 2017;101(7):1628-36.

14. Lee B, Choi Y, Lee W, Park Y, Kim KH, Hyun IG, et al. Timing for Introduction of Total Laparoscopic Living Donor Right Hepatectomy; Initial Experience Based on the Data of Laparoscopic Major Hepatectomy. Transplantation. 2020.

15. Hong SK, Lee KW, Choi Y, Kim HS, Ahn SW, Yoon KC, et al. Initial experience with purely laparoscopic living-donor right hepatectomy. Br J Surg. 2018;105(6):751-9.

16. Kwon CHD, Choi GS, Kim JM, Cho CW, Rhu J, Soo Kim G, et al. Laparoscopic Donor Hepatectomy for Adult Living Donor Liver Transplantation Recipients. Liver Transpl. 2018-24(11):1545-53.

17. Hong SK, Suh KS, Yoon KC, Lee JM, Cho JH, Yi NJ, et al. The learning curve in pure laparoscopic donor right hepatectomy: a cumulative sum analysis. Surg Endosc. 2019;33(11):3741-8.

18. Rhu J, Choi GS, Kwon CHD, Kim JM, Joh JW. Learning curve of laparoscopic living donor right hepatectomy. Br J Surg. 2020; 107(3):278-88.

19. Soubrane 0 , Kwon $\mathrm{CH}$. Tips for pure laparoscopic right hepatectomy in the live donor. J Hepatobiliary Pancreat Sci. 2017;24(2):E1-E5.

20. Suh KS, Hong SK, Lee KW, Yi NJ, Kim HS, Ahn SW, et al. Pure laparoscopic living donor hepatectomy: Focus on 55 donors undergoing right hepatectomy. Am J Transplant. 2018:18(2):434-43

21. Lee JM, Shehta A, Suh KS, Hong SK, Yoon KC, Cho JH, et al. Guidance for Optimal Port Placement in Pure 3-Dimensional Laparoscopic Donor Right Hepatectomy. Liver Transpl. 2019; 25(11):1714-22.

22. Chen KH, Huang CC, Siow TF, Chio UC, Chen SD, Chen YD, et al. Totally laparoscopic living donor right hepatectomy in a donor with trifurcation of bile duct. Asian J Surg. 2016:39(1):51-5.

23. Rotellar F, Pardo F, Benito A, Marti-Cruchaga P, Zozaya G, Lopez $L$, et al. Totally laparoscopic right-lobe hepatectomy for adult living donor liver transplantation: useful strategies to enhance safety. Am J Transplant. 2013;13(12):3269-73.

24. Brustia R, Komatsu S, Goumard C, Bernard D, Soubrane 0, Scatton 0 . From the left to the right: 13-year experience in laparoscopic living donor liver transplantation. Updates Surg. 
2015;67(2):193-200.

25. Kim YS, Choi SH. Pure Laparoscopic Living Donor Right Hepatectomy Using Real-Time Indocyanine Green Fluorescence Imaging. J Gastrointest Surg. 2019;23(8):1711-2.

26. Han YS, Ha H, Kwon HJ, Chun JM. Pure laparoscopic donor right hepatectomy in a living donor with type 3a biliary variation: A case report. Medicine (Baltimore). 2017;96(38):e8076.

27. Hong SK, Lee KW, Kim HS, Yoon KC, Ahn SW, Choi JY, et al. Optimal bile duct division using real-time indocyanine green near-infrared fluorescence cholangiography during laparoscopic donor hepatectomy. Liver Transpl. 2017;23(6):847-52.

28. Rhu J, Kim MS, Choi GS, Jeong WK, Kim JM, Joh JW. A novel technique for bile duct division during laparoscopic living donor hepatectomy to overcome biliary complications in liver transplantation recipients: 'cut and clip' rather than 'clip and cut'. Transplantation. 2020 Aug 18. Online ahead of print.

29. Song JL, Yang J, Wu H, Yan LN, Wen TF, Wei YG, et al. Pure laparoscopic right hepatectomy of living donor is feasible and safe: a preliminary comparative study in China. Surg Endosc. 2018;32(11): 4614-23

30. Rhu J, Choi GS, Kim JM, Joh JW, Kwon CHD. Feasibility of total laparoscopic living donor right hepatectomy compared with open surgery: comprehensive review of 100 cases of the initial stage. J Hepatobiliary Pancreat Sci. 2020;27(1):16-25.

31. Rotellar F, Pardo F, Benito A, Zozaya G, Marti-Cruchaga P, Hidalgo F, et al. Totally Laparoscopic Right Hepatectomy for Living Donor Liver Transplantation: Analysis of a Preliminary Experience on 5 Consecutive Cases. Transplantation. 2017;101(3):548-54

32. Samstein B, Griesemer A, Halazun K, Kato T, Guarrera JV, Cherqui D, et al. Pure Laparoscopic Donor Hepatectomies: Ready for Widespread Adoption? Ann Surg. 2018;268(4):602-9.

33. Shehta A, Lee JM, Lee KW, Hong SK, Cho JH, Yi NJ, et al. Pure Laparoscopic Living Donor Hepatectomy for Donors With Right Portal Vein Anatomical Variations. Liver Transpl. 2019;25(9): 1445-54.

34. Hong SK, Suh KS, Lee JM, Cho JH, Yi NJ, Lee KW. New Technique for Management of Separate Right Posterior and Anterior Portal Veins in Pure 3D Laparoscopic Living Donor Right Hepatectomy. J Gastrointest Surg. 2020;24(2):462-3.

35. Park K, Shehta A, Lee JM, Hong SK, Yoon KC, Cho JH, et al. Pure 3D laparoscopy versus open right hemihepatectomy in a donor with type II and III portal vein variations. Ann Hepatobiliary Pancreat Surg. 2019;23(4):313-8. 